M. Benkahla, R. Taleb, Z. Boudjema

\title{
A NEW ROBUST CONTROL USING ADAPTIVE FUZZY SLIDING MODE CONTROL FOR A DFIG SUPPLIED BY A 19-LEVEL INVERTER WITH LESS NUMBER OF SWITCHES
}

This article presents the powers control of a variable speed wind turbine based on a doubly fed induction generator (DFIG) because of their advantages in terms of economy and control. The considered system consists of a DFIG whose stator is connected directly to the electrical network and its rotor is supplied by a 19-level inverter with less number of switches for minimize the harmonics absorbed by the DFIG, reducing switching frequency, high power electronic applications because of their ability to generate a very good quality of waveforms, and their low voltage stress across the power devices. In order to control independently active and reactive powers provided by the stator side of the DFIG to the grid and ensure high performance and a better execution, three types of robust controllers have been studied and compared in terms of power reference tracking, response to sudden speed variations, sensitivity to perturbations and robustness against machine parameters variations. References 34, tables 4, figures 13.

Key words: wind turbine, doubly fed induction generator, sliding mode controller, adaptive sliding mode controller, adaptive fuzzy sliding mode controller, multilevel inverter.

В статье описывается управление мощностью ветряной турбины переменной скорости на основе асинхронного генератора двойного питания ввиду их преимуществ с точки зрения экономичности и управления. Рассматриваемая система состоит из асинхронного генератора двойного питания, статор которого подключен непосредственно к электрической сети, а его ротор питается от 19-уровневого инвертора с меньшим количеством коммутаторов для минимизации гармоник, поглоцаемых генератором, уменьщая частоту переключения, и устройств силовой электроники вследствие их способности генерировать высокое качество сигналов и низкого уровня напряжения на них. Чтобы независимо управлять активной и реактивной мощностью, подаваемой стороной статора указанного генератора в сеть, и обеспечивать высокую производительность и лучиее конструктивное исполнение, изучены и сопоставлены три типа робастных контроллеров с точки зрения отслеживания мощности, реакции на внезапное изменение скорости, чувствительности к возмущениям и устойчивости к изменениям параметров машины. Библ. 34, табл. 4, рис. 13.

Ключевые слова: ветряная турбина, асинхронный генератор двойного питания, контроллер режима скольжения, адаптивный контроллер режима скольжения, адаптивный нечеткий контроллер режима скольжения, многоуровневый инвертор.

Introduction. Wind energy has the most contribution for power generation among different renewable energy resources; this is so because of its potential advantageous such as free availability of wind, ability to exploit in high power, other land around uses of wind farms and as the important one it is relatively inexpensive to build wind farm [1]. The wind energy community has dedicated a huge effort to develop improved condition monitoring strategies. Fault detection and isolation schemes and fault tolerant control strategies applicable to wind turbines (WT) [2].

Wind power has established itself as a main source for the generation of electricity in the past decade by delivering at least $3.4 \%$ of the world's electricity in 2014 , a figure expected to increase to $6-8 \%$ by 2020 and to $8-17 \%$ by $2030[3,4]$.

In the development of WT technologies doubly fed induction generators (DFIG) are the most popular due to their numerous advantages including independent control of both active and reactive powers, variable speed operation, four-quadrant active and reactive power capabilities, high energy efficiency, and low size converters [5-8]. These advantages are achieved through controlling the rotor voltage or current by a converter while the stator is directly connected to the grid [9].

Research on the control and operation for DFIG under distorted grid voltage conditions has been studied in [10]. Studied in this paper is shown in Fig. 1. In this diagram, mechanical energy is produced by a WT and provided to a DFIG through a gear box. The back-to-back control system and voltage source converters comprise rotor-side and gridside converters. The grid side converter (GSC) is used to control the DC-link voltage and reactive power exchanged with the grid and is connected to the grid via three chokes to improve the current harmonic distortion. The rotor side converter (RSC) is used to control the generator speed and reactive power [11]. The RSC controls the generator to achieve maximum power point tracking. In one classification, the control approaches of the DFIG are categorized in two groups: classic control approaches using PI regulators and advanced control approaches.

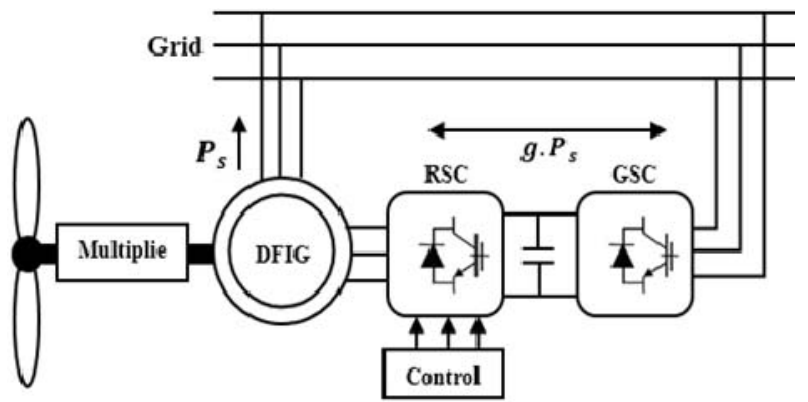

Fig. 1. Diagram of a wind energy conversion system

High power applications in electrical traction require high voltage supply for motors. The only way to use multilevel converters is actually to generate voltages with high magnitudes [12].

Several topologies of multilevel inverters have been studied and presented. Among them, neutral point clamped inverters [13], flying capacitors inverters also called imbricated cells [14], and series connected cells inverters also called cascaded inverters [15]. The industry often has used the neutral-point-clamped inverter [16].

(C) M. Benkahla, R. Taleb, Z. Boudjema 
However, the topology that uses series connected cells inverters presents some advantages, as smaller voltage rate $(d U / d t)$ due to existence of higher number levels, producing less common-mode voltage across motor windings [17]. Furthermore, this topology is simple and its modular configuration makes it easily extensible for any number of desired output voltage levels. Fig. 2, a. shows the basic diagram of this topology with $k$ partial cells represented by Fig. 2, $b$. The $J^{\text {th }}$ single-phase inverter is supplied by a DC-voltage source $U_{d j}(j=1 \ldots k)$. The relationship between the number of series-connected single-phase inverters in each phase and the number of output voltage levels generated by this topology, respectively $k$ and $N$, is given by: $N=2 k+1$, in the case where there are equal voltages in all partial inverters.



Fig. 2. $a-$ a series-connected multilevel inverter topology with $k$ partial cells, $b$ - partial cell configuration

In all the well-known multilevel converter topologies, the number of power devices required depends on the output voltage level needed [18]. However, increasing the number of power semiconductor switches also increases the converter circuit and control complexity and the costs. To provide a large number of output levels without increasing the number of converters, a uniform step asymmetrical multilevel inverters (USAMI) can be used [19].

The sliding mode control achieves robust control by adding a discontinuous control signal across the sliding surface, satisfying the sliding condition. Nevertheless, this type of control has an essential disadvantage, which is the chattering phenomenon caused by the discontinuous control action. To treat these difficulties, several modifications to the original sliding control law have been proposed, the most popular being the boundary layer approach [20,21].

The disadvantages of the structure are complex network structure and inference mechanism. Therefore, to overcome the disadvantages of the aforementioned sliding mode controller (SMC), a new adaptive sliding mode controller (ASMC) is developed to estimate the unknown bound of uncertainty which is obtained in the sense of Lyapunov stability theorem to minimize the control effort and attenuate chattering [22], robustness and rapidity [23]. In addition, estimating the disturbance in terms of the sliding function dynamics is that, it results in a simple linear dynamics and hence the estimator can be made simple [24]. And scheme guarantees asymptotic convergence of states and external disturbances [25]. An adaptive sliding mode controller is developed to track the speed for maximum power extraction.

In order to reduce the chattering problem in SMC, a small boundary layer around the sliding surface. However this method can lead to solve the chattering problem but usually there exist a finite steady state error and so asymptotical convergence is lost. As another solution, adaptive fuzzy sliding mode control (AFSMC) [26]. An
AFSMC was proposed by combining the tuning online characteristic of an AFC and the robust characteristic of a conventional SMC. In an AFSMC, the controller includes two parts: a fuzzy equivalent controller designed based on an AFC scheme and a reaching controller based on a SMC scheme [27]. An AFSMC that control the uncertain nonlinear chaotic systems and unknown robotic systems [28], the controller proposed is composed of two terms: an auxiliary control law which is designed to compensate and uncertainties of parameters and a primary control law which ensure a good tracking. Another advantages of this controller is the using of Lyapunov approach to guarantee the stability and convergence analysis [29]. As another solution to eliminate chattering phenomenon and achieve zero steady state error [26].

System modeling. The WT model. For a horizontal axis wind turbine, the output mechanical power extracted from the wind is given by [30]:

$$
P_{t}=\frac{1}{2} P_{\text {Coef }}(\lambda, \beta) \pi R^{2} \rho v^{3},
$$

where $P_{C o e f}$ is the power coefficient which is a function of both tip speed ratio $\lambda$, and blade pitch angle $\beta$ (deg), and $v$ is the wind speed $(\mathrm{m} / \mathrm{s}), \rho$ is the air density $\left(\mathrm{kg} / \mathrm{m}^{3}\right)$, and $R$ is the radius of the turbine (m). In this work the $P_{C o e f}$ equation is approximated using a non-linear function according to [31]:

$$
\begin{aligned}
& P_{\text {Coef }}=(0.5-0.167)(\beta-2) \sin \left[\frac{\pi(\lambda+0.1)}{18.5-0.3(\beta-2)}\right]- \\
& -0.0018(\lambda-3)(\beta-2) .
\end{aligned}
$$

The tip speed ratio is given by:

$$
\lambda=\Omega_{t} R / v,
$$

where $\Omega_{t}$ is the angular velocity of WT.

Proposed 19-level USAMI. Multilevel inverters generate at the AC-terminal several voltage levels as close as possible to the input signal. The output voltage step is defined by the difference between two consecutive voltages. A multilevel converter has a uniform or regular voltage step, if the steps $\Delta u$ between all voltage levels are equal. In this case the step is equal to the smallest DCvoltage, $u_{d 1}$ [32]. This can be expressed by

$$
u_{d 1}=\Delta u=u_{s 2}-u_{s 1}=u_{s 3}-u_{s 2}=\ldots=u_{s N}-u_{s(N-1)}
$$

If this is not the case, the converter is called a non uniform step CHBAMI or irregular CHBAMI. An USCHBAMI is based on DC-voltage sources to supply the partial cells (inverters) composing its topology which respects to the following conditions:

$$
\left\{\begin{array}{l}
u_{d 1} \leq u_{d 2} \leq \ldots \leq u_{d k} \\
u_{d j} \leq 1+2 \sum_{l=1}^{j-1} u_{d l},
\end{array}\right.
$$

where $k$ represents the number of partial cells per phase and $j=1 \ldots k$.

The number of output voltage levels depends on the number of cells per phase and on the corresponding supplying DC-voltages. Equation 6 shows that in certain cases, there are many possibilities for setting the partial DC-voltages to obtain the same number of levels. These possible redundant solutions are another degree of freedom for the designer

$$
N=1+2 \sigma_{k} \text { where } \sigma_{k}=\sum_{j=1}^{k} u_{d j} .
$$


Table 1 gives some examples of the DC-voltages which can be set and the corresponding number of output voltage levels which can be obtained. In this example there are $k=3$ series-connected single-phase inverters per phase.

Table 1

Examples of unequal DC-voltages in a 3 cells USAMI

\begin{tabular}{|c|c|c|c|}
\hline$u_{d 1}(p . u)$. & $u_{d 2}(p . u)$. & $u_{d 3}(p . u)$. & $N$ \\
\hline 1 & 1 & 2 & 9 \\
\hline 1 & 1 & 3 & 11 \\
1 & 2 & 2 & 13 \\
\hline 1 & 1 & 4 & \\
1 & 2 & 3 & 19 \\
1 & 1 & 7 & \\
1 & 2 & 6 & \\
\hline
\end{tabular}

Among several modulation strategies, the multicarrier sub-harmonic PWM technique has been receiving an increasing attention for symmetrical multilevel converters [33]. This modulation method can also be used to control asymmetrical multilevel power converters.

The SPWM is also known as the multi-carrier PWM because it relies on a comparison between a sinusoidal reference waveform and vertically shifted carrier waveforms $N-1$ carriers are therefore required to generate $N$ levels. The carriers are in continuous bands around the zero reference. They have the same amplitude $A_{c}$ and the same frequency $f_{c}$. The sine reference waveform has a frequency $f_{r}$ and an amplitude $A_{r}$. At each instant, the result of the comparison is 1 if the triangular carrier is greater than the reference signal and 0 otherwise. The output of the modulator is the sum of the different comparisons which represents the voltage level. The strategy is therefore characterized by the two following parameters, respectively called the modulation index and the modulation rate:

$$
\begin{gathered}
m=f_{c} / f_{r} ; \\
r=\frac{2}{N-1} \cdot \frac{A_{r}}{A_{c}} .
\end{gathered}
$$

The reference voltages are given as follows:

$$
\left\{\begin{array}{l}
u_{r i}=u_{r \max } \sin \left(2 \pi f_{r} t-(j-1) 2 \pi / 3\right) \\
(i, j) \in\{(a, 1),(b, 2),(c, 3)\} .
\end{array}\right.
$$

We propose to develop a 19-level USAMI composed of $k=3$ partial inverters per phase with the following DCvoltage sources: $u_{d 1}=1 p . u, u_{d 2}=3 p . u$ and $u_{d 3}=5 p . u$. For this configuration $(1,3,5)$, the total harmonic distortion (THD) of output voltage is smaller than configurations $(1,1,7)$ and $(1,2,6)$. Fig. 3 shows the output voltage in each partial inverter and the 19-level USAMI output voltage $V_{a}$ in the first leg.
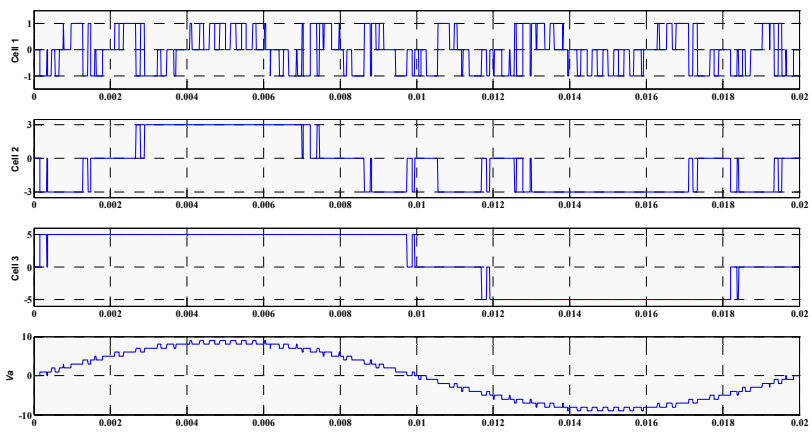

Fig. 3. Output voltages of the partial H-bridges, and total output voltage of the 19-level USAMI
Doubly fed induction generator modeling. The dynamic voltages and fluxes equations of the DFIG in a synchronous reference frame $(d-q)$ rotating at an angular speed of $\omega_{s}$. The stator and rotor voltages are given, respectively, as follows:

$$
\left\{\begin{array}{l}
V_{d s}=R_{s} I_{d s}+\frac{d}{d t} \psi_{d s}-\omega_{s} \psi_{q s} ; \\
V_{q s}=R_{s} I_{q s}+\frac{d}{d t} \psi_{q s}+\omega_{s} \psi_{d s} ; \\
V_{d r}=R_{r} I_{d r}+\frac{d}{d t} \psi_{d r}-\omega_{r} \psi_{q r} ; \\
V_{q r}=R_{r} I_{q r}+\frac{d}{d t} \psi_{q r}+\omega_{r} \psi_{d r}
\end{array} ;\left\{\begin{array}{l}
\psi_{d s}=L_{s} I_{d s}+M I_{d r} \\
\psi_{q s}=L_{s} I_{q s}+M I_{q r} \\
\psi_{d r}=L_{r} I_{d r}+M I_{d s} \\
\psi_{q r}=L_{r} I_{q r}+M I_{q s}
\end{array}\right.\right.
$$

The stator and rotor angular velocities are linked by the following relation: $\omega_{s}=\omega+\omega_{r}$. The generator mechanical and electromagnetic torques $\left(C_{e m}\right.$ and $\left.C_{r}\right)$ are related, if the viscous friction coefficient is taken into account, as follows:

$$
C_{e m}=C_{r}+J \frac{d \Omega}{d t}+f \Omega,
$$

where the electromagnetic torque $C_{e m}$ is defined by:

$$
C_{e m}=p \frac{M}{L_{s}}\left(\psi_{q s} I_{d r}-\psi_{d s} I_{q r}\right) .
$$

Field oriented control of the DFIG. In order to easily control the production of electricity by the wind turbine, we will carry out an independent control of active and reactive powers by orientation of the stator flux. By choosing a diphase reference frame $d-q$ related to the stator spinning field pattern and aligning the stator vector flux with the axis $d$, we can write

$$
\psi_{d s}=\varphi_{s} \quad \text { and } \quad \psi_{q s}=0 .
$$

The electromagnetic torque becomes:

$$
C_{e m}=-p \frac{M}{L_{s}} I_{q r} \psi_{d s}
$$

The following rotor flux and the stator voltage can be rewritten as:

$$
\begin{gathered}
\left\{\begin{array}{l}
\psi_{s}=L_{s} I_{d s}+M I_{d r} \\
0=L_{s} I_{q s}+M I_{q r}
\end{array}\right. \\
\left\{\begin{array}{l}
V_{d s}=0 \\
V_{q s}=\omega_{s} \psi_{s} .
\end{array}\right.
\end{gathered}
$$

By supposing that the electrical supply network is stable, having for simple voltage $V_{S}$, which led to a stator flux $\psi_{S}$ constant. This consideration associated with Equation (15) shows that the electromagnetic torque only depends on the $q$-axis rotor current component. Using Equation (16), a relation between the stator and rotor currents can be established

$$
\left\{\begin{array}{l}
I_{d s}=-\frac{M}{L_{s}} I_{d r}+\frac{\psi_{s}}{L_{s}} \\
I_{q s}=-\frac{M}{L_{s}} I_{q r} .
\end{array}\right.
$$

The stator active and reactive powers are written

$$
\left\{\begin{array}{l}
P_{s}=V_{d s} I_{d s}+V_{q s} I_{q s} \\
Q_{s}=V_{q s} I_{d s}-V_{d s} I_{q s} .
\end{array} .\right.
$$

By using Equation (10), (16-18), the statoric active and reactive power, the rotoric fluxes and voltages can be written versus rotoric currents as 


$$
\begin{gathered}
\left\{\begin{array}{l}
P_{s}=-\frac{\omega_{s} \psi_{s} M}{L_{s}} I_{q r} \\
Q_{s}=-\frac{\omega_{s} \psi_{s} M}{L_{s}} I_{d r}+\frac{\omega_{s} \psi_{s}{ }^{2}}{L_{s}} .
\end{array}\right. \\
\left\{\begin{array}{l}
\psi_{d r}=\left(L_{r}-\frac{M^{2}}{L_{s}}\right) I_{d r}+\frac{M \psi_{s}}{L_{s}} ; \\
\psi_{q r}=\left(L_{r}-\frac{M^{2}}{L_{s}}\right) I_{q r} .
\end{array}\right. \\
\left\{\begin{array}{l}
V_{d r}=R_{r} I_{d r}+\left(L_{r}-\frac{M^{2}}{L_{s}}\right) \frac{d I_{d r}}{d t}-g \omega_{s}\left(L_{r}-\frac{M^{2}}{L_{s}}\right) I_{q r} \\
V_{q r}=R_{r} I_{q r}+\left(L_{r}-\frac{M^{2}}{L_{s}}\right) \frac{d I_{q r}}{d t}+g \omega_{s}\left(L_{r}-\frac{M^{2}}{L_{s}}\right) I_{d r}+g \omega_{s} \frac{M \psi_{s}}{L_{s}} .
\end{array}\right.
\end{gathered}
$$

In steady state, the second derivative terms of the two equations in 21 are nil.

We can thus write:

$$
\left\{\begin{array}{l}
V_{d r}=R_{r} I_{d r}-g \omega_{s}\left(L_{r}-\frac{M^{2}}{L_{s}}\right) I_{q r} ; \\
V_{q r}=R_{r} I_{q r}+g \omega_{s}\left(L_{r}-\frac{M^{2}}{L_{s}}\right) I_{d r}+g \omega_{s} \frac{M \psi_{s}}{L_{s}} .
\end{array}\right.
$$

The third term, which constitutes cross-coupling terms, can be neglected because of their small influence. These terms can be compensated by an adequate synthesis of the regulators in the control loops.

With the hypothesis that led to a stator flux $\psi_{S}$ constant, the electrical supply network is stable, having for simple voltage $V_{S}$.

Control strategies of the DFIG. In this section, we have chosen to compare the performances of the DFIG with three different nonlinear controllers: SMC, ASMC and AFSMC. The control system can be designed as shown in Fig. 4. Based on Equations (18) and (21), the blocks $R_{P}, R_{O}$, $R_{I q r}$ and $R_{I d r}$ represent respectively the stator powers and the rotor currents regulators.

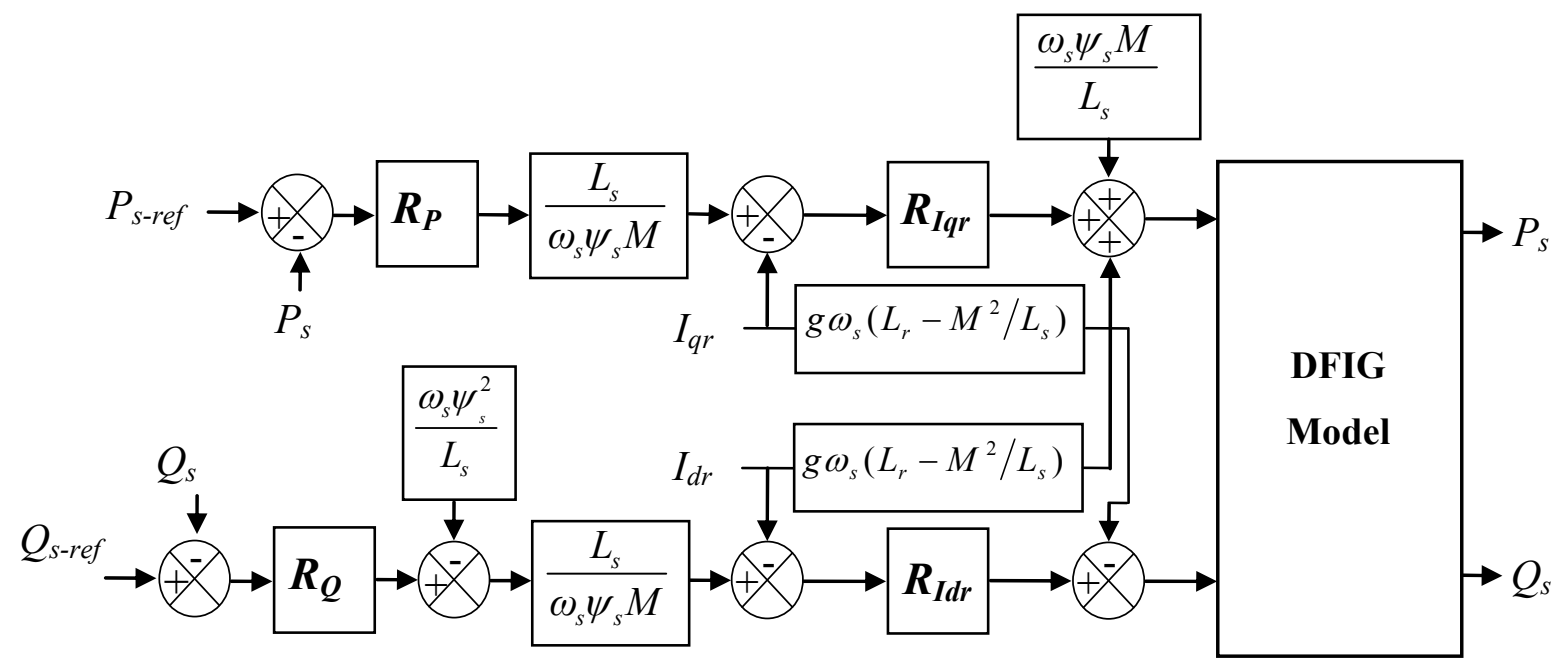

Fig. 4. Power control of the DFIG

Sliding mode controller synthesis. The sliding mode technique is developed from variable structure control to solve the disadvantages of other designs of nonlinear control systems. The sliding mode is a technique to adjust feedback by previously defining a surface. The system which is controlled will be forced to that surface, then the behavior of the system slides to the desired equilibrium point. The control function will satisfy reaching conditions in the following form:

$$
V_{c o m}=V_{e q}+K \cdot \operatorname{sat}(S(x) / \delta) \text {. }
$$

$K$ is a constant and is chosen to compensate for uncertainties and disturbances, $\operatorname{sat}(S(x) / \delta)$ is the proposed saturation function, is the boundary layer thickness. In this paper we propose the Slotine method

$$
S(X)=\left(\frac{d}{d t}+\lambda\right)^{n-1} e,
$$

here $e$ is the tracking error vector, $\lambda$ is a positive coefficient and $n$ is the relative degree.

In our study, the control of the active stator power $P_{S}$ and reactive stator power $Q_{S}$ to their references $P_{S}$ ref and $Q_{S}$ ref respectively. The SMC control scheme is shown in Fig. 5, we choose the error between the measured and references stator powers as sliding mode surfaces, so we can write the following expression

$$
\left\{\begin{array}{l}
S_{d}=P_{S_{-} r e f}-P_{S} \\
S_{q}=Q_{S_{-} r e f}-Q_{S}
\end{array}\right.
$$

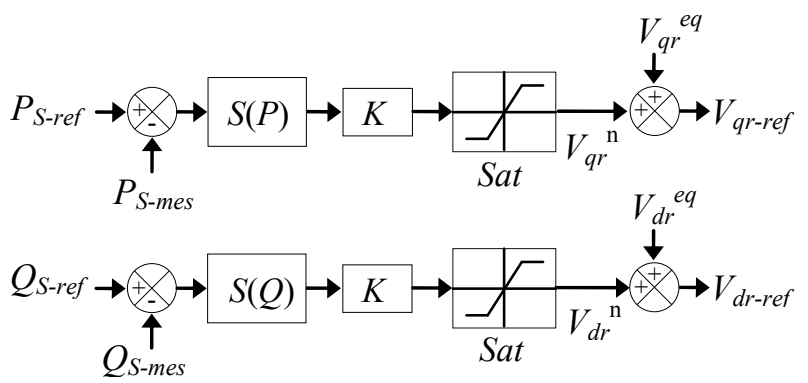

Fig. 5. Block diagram of the sliding mode controller (SMC)

The first order derivate of (25) gives

$$
\left\{\begin{array}{l}
\dot{S}_{d}=\dot{P}_{S_{-} r e f}-\dot{P}_{S} \\
\dot{S}_{q}=\dot{Q}_{S_{-} r e f}-\dot{Q}_{S}
\end{array}\right.
$$

Replacing the powers in (26) by their expressions given in (19), one obtains 


$$
\left\{\begin{array}{l}
\dot{S}_{d}=\dot{P}_{S_{-} r e f}-\frac{\omega_{s} \psi_{s} M}{L_{s}} \dot{I}_{q r} \\
\dot{S}_{q}=\dot{Q}_{S_{-} r e f}-\frac{\omega_{s} \psi_{s} M}{L_{s}} \dot{I}_{d r}-\frac{\omega_{s} \psi_{s}^{2}}{L_{s}} .
\end{array}\right.
$$

$V_{d r}$ and $V_{q r}$ will be the two components of the control vector used to constraint the system to converge to $S_{d q}=0$. The control vector $V_{d q e q}$ is obtained by imposing $\dot{S}_{d q}=0$. So the equivalent control components are given by the following relation

$$
V_{\text {eqdq }}=\left[\begin{array}{l}
-\frac{L_{s}\left(L_{r}-\frac{M^{2}}{L_{s}}\right)}{\omega_{s} \psi_{s} M} \dot{Q}_{s}^{*}+R_{r} I_{d r}-\left(L_{r}-\frac{M^{2}}{L_{s}}\right) g \omega_{s} I_{q r}+\frac{\left(L_{r}-\frac{M^{2}}{L_{s}}\right) \psi_{s}}{M} \\
\frac{L_{s}}{\omega_{s} \psi_{s} M} \dot{P}_{s}^{*}+R_{r} I_{q r}-\left(L_{r}-\frac{M^{2}}{L_{s}}\right) g \omega_{s} I_{d r}+\frac{g \omega_{s} \psi_{s} M}{L_{s}}
\end{array}\right]
$$

To obtain good performances, dynamic and commutations around the surfaces, the control vector is imposed as follows

$$
V_{d q}=V_{e q d q}+K \cdot \operatorname{sat}\left(S_{d q}\right)
$$

The sliding mode will exist only if the following condition is met

$$
S \dot{S}<0 .
$$

Adaptive sliding mode controller. The main obstacles for application of sliding mode control are two phenomena: high activity of control action and chattering. In this section we propose an adaptive sliding mode controller whose switching gain is adapted based on the disturbance estimation, this control proposed in [34]. The ASMC could be considered as an advance version of basic sliding mode control that is also in the topics of many advance control studies. The ASMC control scheme is shown in Fig. 6. This method is often used low overshoot, low setting time, and robustness against disturbance, chattering reduction, no need for the prior knowledge of uncertainty bound, minimum control effort. The control input in the ASMC is given in

$$
V_{c o m}=V_{e q}+V_{A S M C} \text {. }
$$

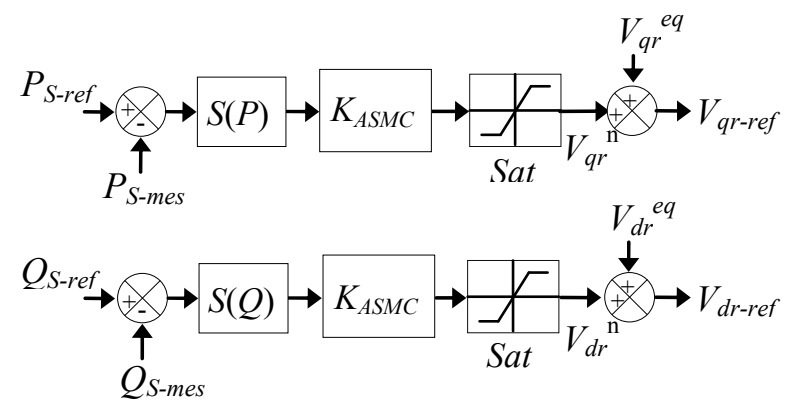

Fig. 6. Block diagram of the adaptive sliding mode control (ASMC)

$V_{A S M C}$ is obtained by

$$
V_{A S M C}=K_{\text {asmc }}(t) \operatorname{sat}(S(x) / \delta),
$$

where $K_{a s m c}(t)$ is the reaching gain which is achieved by adaptation law

$$
\dot{K}_{\text {asmc }}(t)=-\gamma\|s\|,
$$

where $\gamma$ is a positive constant and $K_{a s m c}(t)$ is the adaptive controller gain. This control law makes $K_{\text {asmc }}(t)$ to increase until the system reaches the switching manifold. Whenever $S=0$ is not reachable in practical SMC which causes an increasing $K_{a s m c}(t)$ and high gain introduces chattering. Further, $\dot{K}_{a s m c}(t)=0$ which results in saturation of the control gain $K_{a s m c}(t)$.

Adaptive fuzzy sliding mode controller. The disadvantage of sliding mode controllers is that the discontinuous control signal produces chattering. In order to eliminate the chattering phenomenon, we propose to use the adaptive fuzzy sliding mode control. This paper proposes an AFSMC which is designed to control the active and reactive power of the DFIG shown in Fig. 7. Besides advantage of stability and robustness and convergence of the control system are guaranteed by using the Lyapunov method. This control following from

$$
V_{\text {com }}=V_{e q}+V_{A F S M C} \text {. }
$$

$V_{A F S M C}$ is obtained by

$$
\begin{gathered}
V_{A F S M C}=K_{a s m c}(t) V_{\text {Fuzzy }} ; \\
V_{\text {Fuzzy }}=\operatorname{sat}(S(x) / \delta) .
\end{gathered}
$$

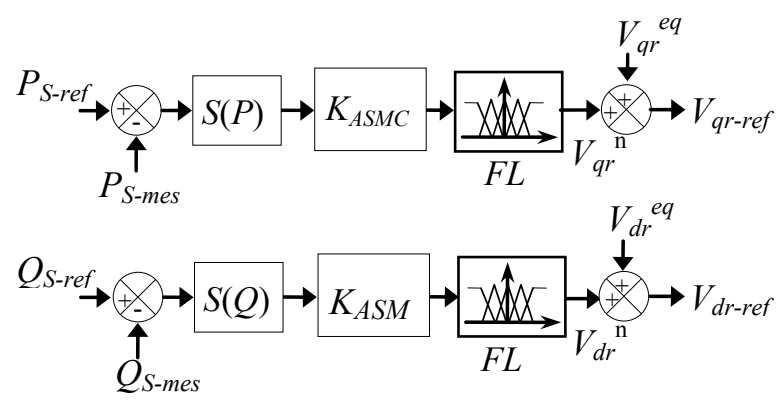

Fig. 7. Block diagram of the Adaptive Fuzzy Sliding Mode Control (AFSMC)

The fuzzy sliding mode controller (FSMC) is a modification of the sliding mode controller, where the switching controller term $\operatorname{sat}(S(x) / \delta)$, and $K_{\text {asmc }}(t)$ is obtained by Equation (33), the universes of discourses are first partitioned into the seven linguistic variables NB, NM, NS, EZ, PP, PM, PG, triangular membership functions are chosen to represent the linguistic variables and fuzzy singletons for the outputs are used. The fuzzy rules that produce these control actions are reported in Table 2.

Table 2

\begin{tabular}{|c|c|c|c|c|c|c|c|}
\hline $\mathbf{E}$ & NB & NM & NS & EZ & PS & PM & PB \\
\hline NB & NB & NB & NB & NB & NM & NS & EZ \\
\hline NM & NB & NB & NB & NM & NS & EZ & PS \\
\hline NS & NB & NB & NM & NS & EZ & PS & PM \\
\hline EZ & NB & NM & NS & EZ & PS & PM & PB \\
\hline PS & NM & NS & EZ & PS & PM & PB & PB \\
\hline PM & NS & EZ & PS & PM & PB & PB & PB \\
\hline PB & EZ & PS & PM & PB & PB & PB & PB \\
\hline
\end{tabular}

We use the following designations for membership functions: NB: Negative Big, NS: Negative Small, PS: Positive Small, PB: Positive Big, NM: Negative Middle, EZ: Equal Zero, PM: Positive Middle. These choices are described in Fig. 8.

Simulation results and discussions. In this section, simulation are realized with a $7.5 \mathrm{KW}$ generator coupled to a $380 \mathrm{~V} / 50 \mathrm{~Hz}$ grid. Parameters of the machine are given in Appendix A. With an aim to evaluate the performances of the three controllers: SMC, ASMC and AFSMC, three 
types of tests have been realized: reference tracking, sensitivity to the speed variation and robustness against machine parameter variations.
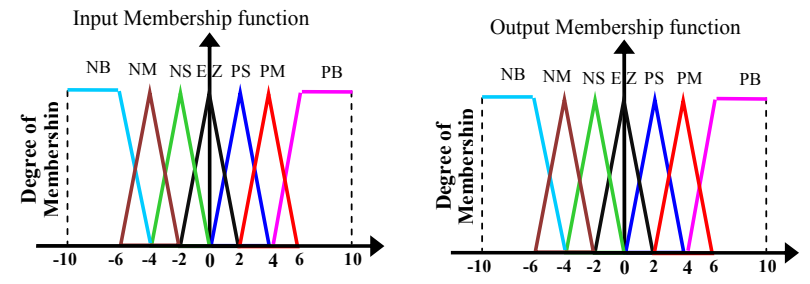

Fig. 8. Fuzzy sets and its memberships functions

Reference tracking. This goal of this test is the study of the behavior of the three controllers in reference tracking, while the machine's speed is considered constant and equal to its nominal value. Simulation results are presented in Fig. 9. As it's shown by this Figure, for the

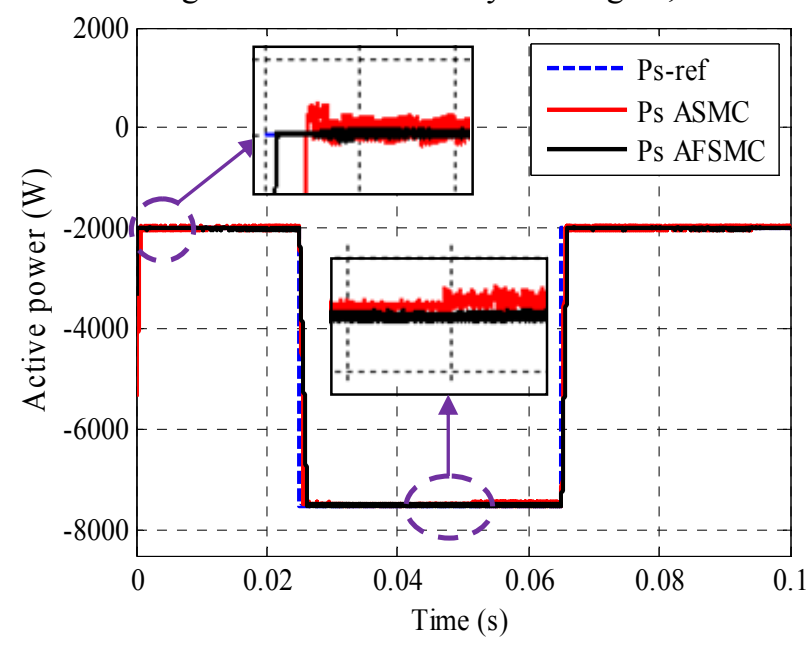

Fig. 9. Reference tracking test
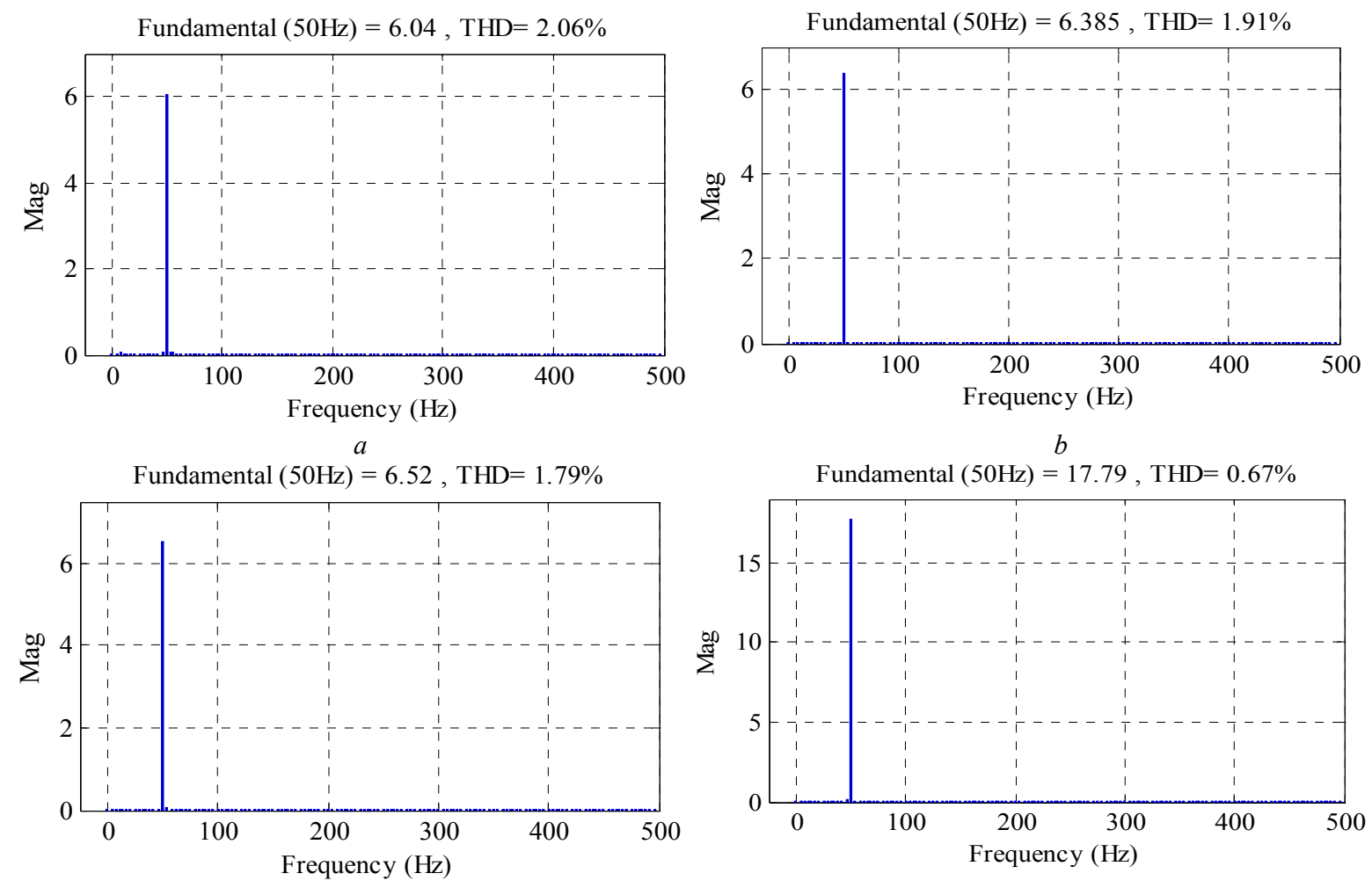

three controllers, the stator active and reactive generated powers tracks almost perfectly their reference and ensures a perfect decoupling between the two axes. Therefore it can be considered that the three types or controllers have a very good performance for this test. On the other hand, Fig. 10 shows the harmonic spectrum of one phase stator current of the DFIG obtained using Fast Fourier Transform (FFT) technique for the three controllers. It can be clear observed that the THD is reduced for AFSMC supplied by 19-level USAMI $(\mathrm{THD}=0.67 \%)$ when compared to AFSMC $(\mathrm{THD}=1.79 \%)$ and ASMC $(\mathrm{THD}=1.91 \%)$ and SMC $(\mathrm{THD}=2.06 \%)$ supplied by conventional inverter (i.e. 2-level inverter). Therefore it can be concluded that proposed controller (AFSMC) supplied by 19-level USAMI is the most effective in eliminating chattering phenomenon and to reduce the current harmonics.



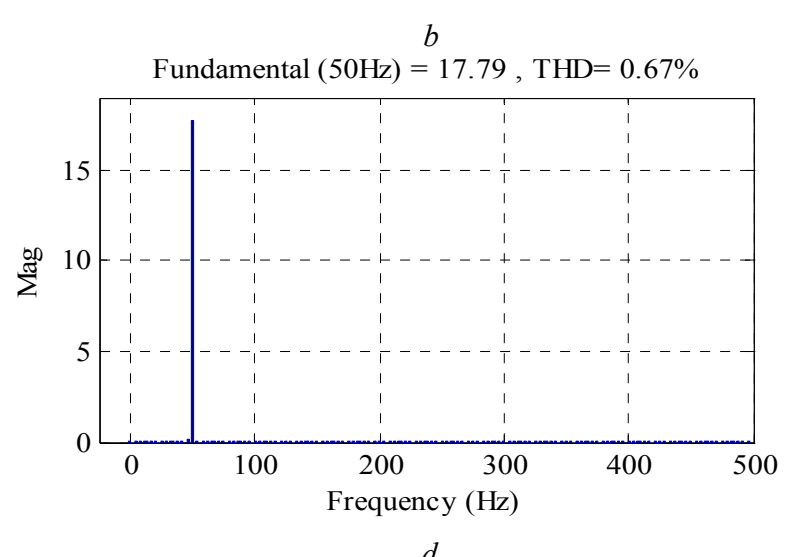

Fig. 10. Spectrum harmonic of one phase stator current for 1) supplied by conventional inverter: SMC (a), $\operatorname{ASMC}(b), \operatorname{AFSMC}(c)$, 2) supplied by 19-level USAMI: AFSMC (d) 
Sensitivity to the speed variation. The main object of this test is to analyze the influence of a speed variation of the DFIG on reactive and active powers for three controllers. For this objective and at time $t=0.04 \mathrm{~s}$, the speed was varied from $150 \mathrm{rad} / \mathrm{s}$ to $170 \mathrm{rad} / \mathrm{s}$ as its shown in Fig. 11. Simulation results are shown in Fig. 12.

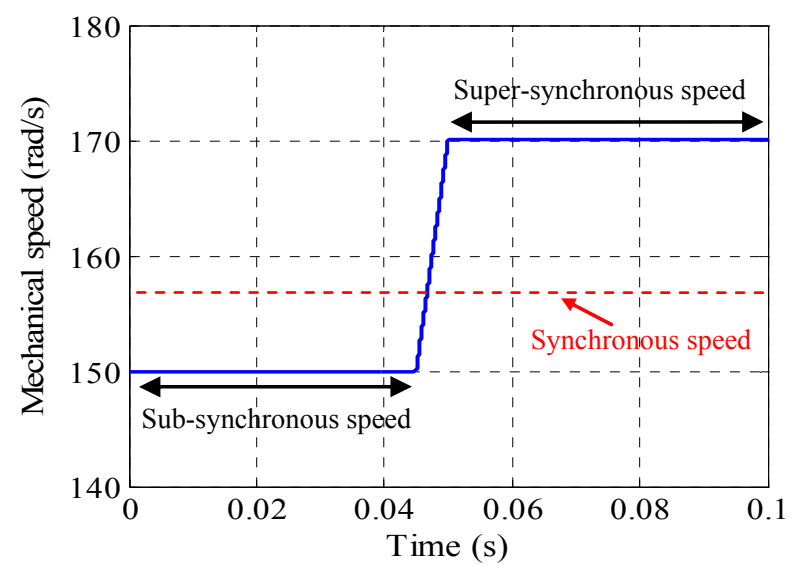

Fig. 11. Mechanical speed profile
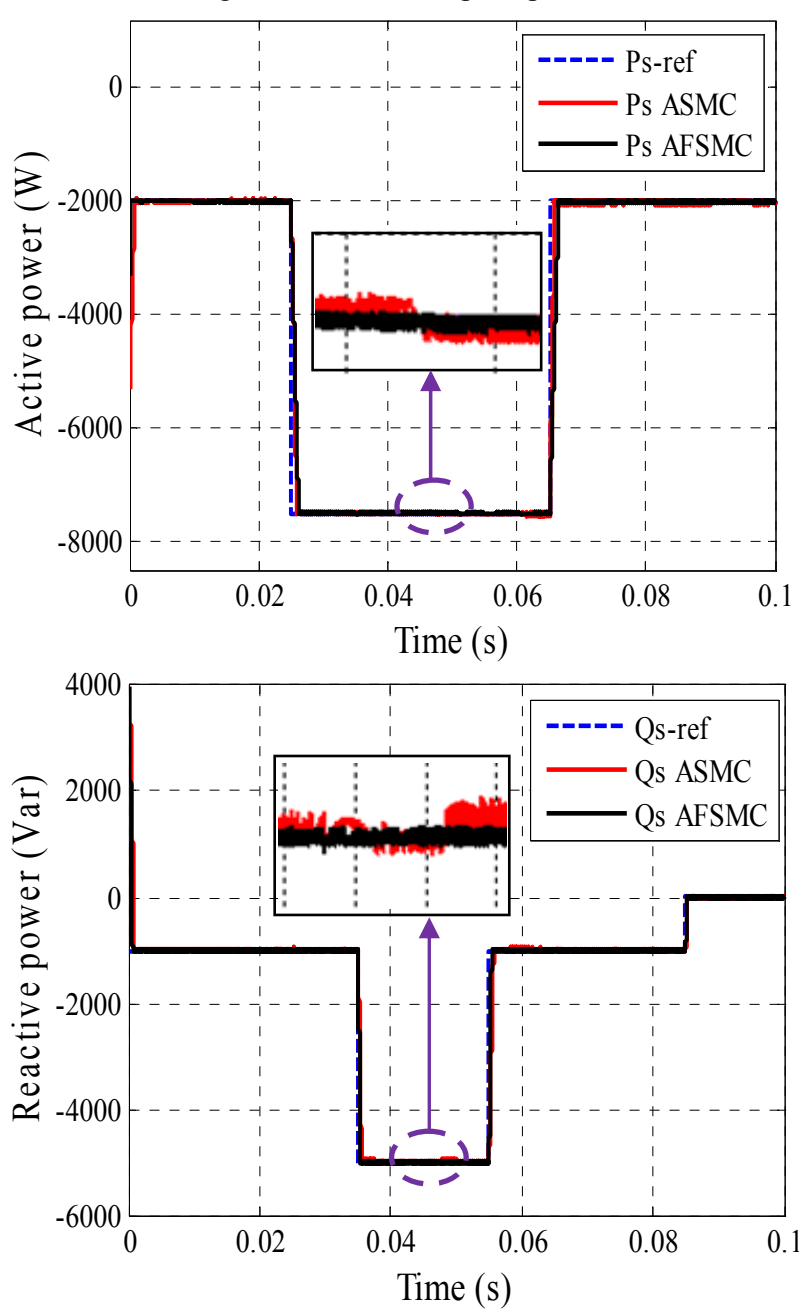

Fig. 12. Sensitivity to the speed variation

This figure express that the speed variation produces a slight effect on the powers curves of the system with ASMC controller, while effect is almost negligible for the system with AFSMC one. It can be noticed that this last has a nearly perfect speed disturbance rejection; indeed only very small power variation can be observed (fewer than $2 \%$ ). This result is attractive for wind energy application quality and to ensure stability of the generated power when the sped is varying.

Robustness tests. The aim of these tests is to analyze the influence of the DFIG's parameters variation on the controllers' performance. The DFIG is running at its nominal speed. To test the robustness of the used controllers, parameters of the machine have been modified as follows: the values of the rotor and stator resistances are doubled while the values of inductances $L_{s}$, $L_{r}$ and $M$ are divided by 2 . The obtained results are presented in Fig. 13. These results show that parameters variation of the DFIG presents a clear effect on the powers curves (especially in their errors curves) and that the effect appears more significant for ASMC controller than that with AFSMC one. Thus it can be concluded that this last is the most robust among the proposed controllers studied in this work.
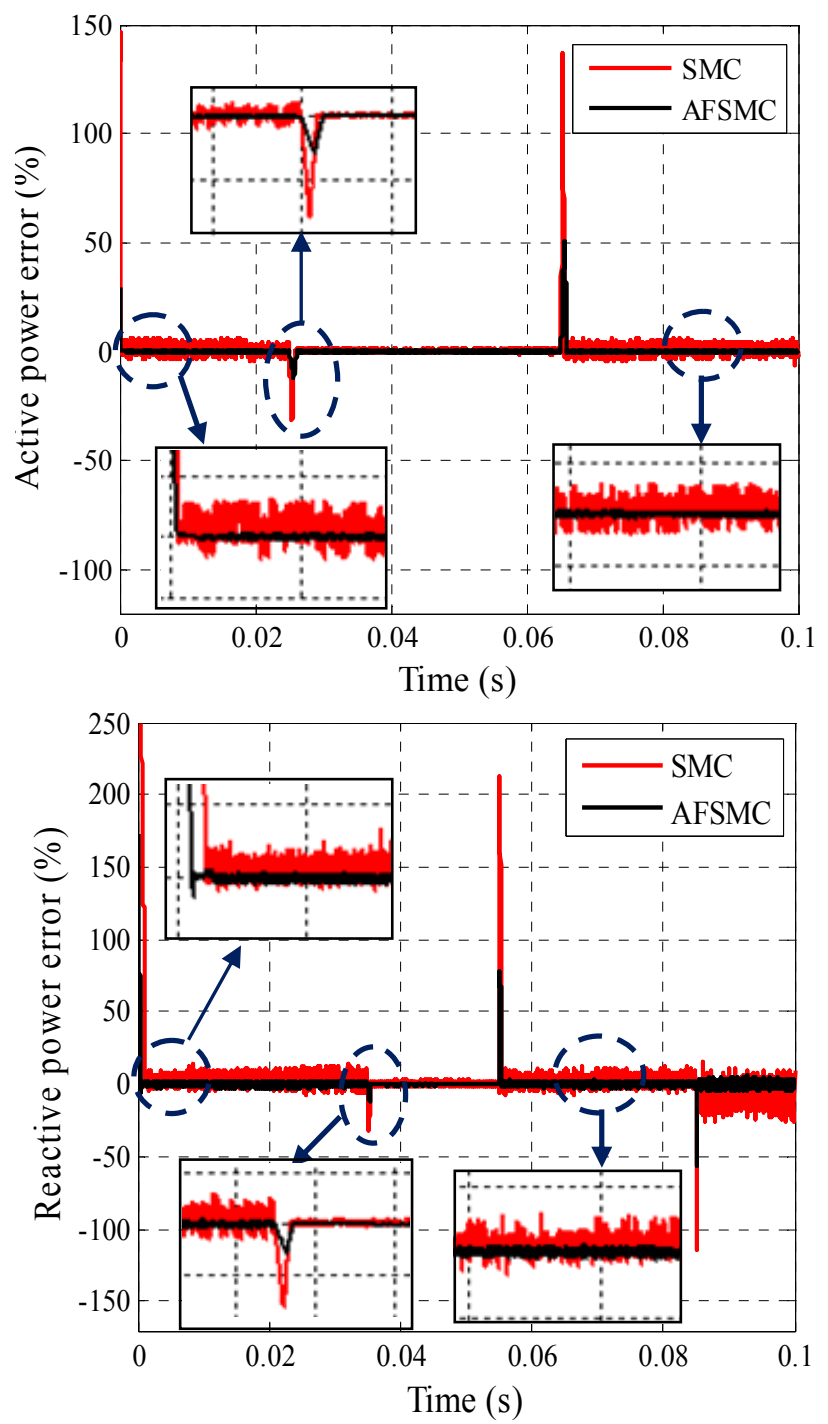

Fig. 13. Effect of machine's parameters variation on the robust control of the DFIG

Conclusion. The modeling and the control of a WT conversion system based on a DFIG connected directly to the grid by the stator side and fed by a 19-level inverter USAMI on the rotor side has been presented in this paper. This kind of variable speed systems has several advantages over the traditional WT operating 
methods, such as an increase in the energy captured and the reduction of the mechanical stress. Our objective was the implementation of a robust decoupled control system of active and reactive powers generated by the stator side of the DFIG in order to make the system insensible with the external disturbances, parametric variations and to ensure a better execution of the DFIG. In the first step, we started with a study of modeling on the whole system. In second step, we present a vector control strategy in order to control active and reactive power exchanged between the stator the DFIG and the grid. In third step, three different controllers are synthesized and compared. In term of power reference tracking with the DFIG in ideal conditions, the SMC ensures a perfect decoupling between the two axes comparatively to the other controllers where the coupling effect between them is clear. The phenomenon of «chattering» associated with the control by sliding mode has a major drawback because it can excite the dynamics of high frequency control which makes it undesirable. In order to eliminate the chattering, we propose to use the AFSMC. Basing on all these results we conclude that robust control method as AFSMC can be a very attractive solution for devices using DFIG such as wind energy conversion systems and establish its suitability for the system drive.

\section{Appendix A}

Machine parameters

\begin{tabular}{|c|c|c|}
\hline Parameters & Value & IS-Unit \\
\hline Nominal power & 7.5 & $\mathrm{~kW}$ \\
\hline Turbine radius & 35.5 & $\mathrm{~m}$ \\
\hline Gearbox gain & 90 & \\
\hline Stator voltage & 398 & $\mathrm{~V}$ \\
\hline Stator frequency & 50 & $\mathrm{~Hz}$ \\
\hline Number of pairs poles & 2 & \\
\hline Nominal speed & 150 & $\mathrm{rad} / \mathrm{s}$ \\
\hline Rotor resistance & 0.62 & $\Omega$ \\
\hline Stator inductance & 0.084 & $\mathrm{H}$ \\
\hline Rotor inductance & 0.081 & $\mathrm{H}$ \\
\hline Mutual inductance & 0.078 & $\mathrm{H}$ \\
\hline Inertia & 0.01 & $\mathrm{Kg} \cdot \mathrm{m}^{2}$ \\
\hline
\end{tabular}

Appendix B

List of symbols

\begin{tabular}{|c|c|}
\hline Symbol & Significance \\
\hline$V_{d s}, V_{q s}, V_{d r}, V_{q r}$ & Two-phase stator and rotor voltages \\
\hline$\psi_{q s}, \psi_{d s}, \psi_{q r}, \psi_{d r}$ & Two-phase stator and rotor fluxes \\
\hline$I_{d s}, I_{q s}, I_{d r}, I_{q r}$ & Two-phase stator and rotor currents \\
\hline$R_{s}, R_{r}$ & Per phase stator and rotor resistances \\
\hline$L_{s}, L_{r}$ & Per phase stator and rotor inductances \\
\hline$M$ & Mutual inductance \\
\hline$p$ & Number of pole pairs \\
\hline$s$ & Laplace operator \\
\hline$\omega_{s}, \omega_{r}$ & Stator and rotor currents frequencies $(\mathrm{rad} / \mathrm{s})$ \\
\hline$\omega$ & Mechanical rotor frequency $(\mathrm{rad} / \mathrm{s})$ \\
\hline$P_{s}, Q_{s}$ & Active and reactive stator power \\
\hline$J$ & Inertia \\
\hline$f$ & Coefficient of viscous frictions \\
\hline$C_{r}$ & Load torque \\
\hline$C_{e m}$ & Electromagnetic torque \\
\hline
\end{tabular}

\section{REFERENCES}

1. Ellabban O., Abu-Rub H., Blaabjerg F. Renewable energy resources: Current status, future prospects and their enabling technology. Renewable and Sustainable Energy Reviews, 2014, vol.39, pp. 748-764. doi: 10.1016/j.rser.2014.07.113.

2. de Bessa I.V., Palhares R.M., D’Angelo M.F.S.V., Chaves Filho J.E. Data-driven fault detection and isolation scheme for a wind turbine benchmark. Renewable Energy, 2016, vol.87, pp. 634-645. doi: 10.1016/j.renene.2015.10.061.

3. GWEC: Global Wind Energy Outlook 2014. Available at: http://www.gwec.net/wp-

content/uploads/2014/10/GWEO2014 WEB.pdf (accessed 02 May 2017).

4. World Wind Energy Market Update, Navigant Research, 2015. Available

http://www.provedor.nuca.ie.ufrj.br/estudos/navigant1.pdf (accessed 15 October 2016).

5. Cardenas R., Pena R., Alepuz S., Asher G. Overview of Control Systems for the Operation of DFIGs in Wind Energy Applications, IEEE Transactions on Industrial Electronics, 2013, vol.60, no.7, pp. 2776-2798. doi: 10.1109/tie.2013.2243372.

6. Tazil M., Kumar V., Bansal R.C., Kong S., Dong Z.Y., Freitas W. Three-phase doubly fed induction generators: an overview. IET Electric Power Applications, 2010, vol.4, no.2, p.

75. doi: 10.1049 /iet-epa.2009.0071

7. Marques G.D., Sousa D.M. Air-Gap-Power-Vector-Based Sensorless Method for DFIG Control Without Flux Estimator. IEEE Transactions on Industrial Electronics, 2011, vol.58, no.10, pp. 4717-4726. doi: 10.1109/tie.2011.2107716.

8. Kamh M.Z., Iravani R. Three-Phase Steady-State Model of Type-3 Wind Generation Unit - Part I: Mathematical Models. IEEE Transactions on Sustainable Energy, 2011, vol.2, no.4, pp. 477-486. doi: 10.1109/tste.2011.2156821.

9. Jadhav H.T., Roy R. A comprehensive review on the grid integration of doubly fed induction generator. International Journal of Electrical Power \& Energy Systems, 2013, vol.49, pp. 8-18. doi: 10.1016/j.ijepes.2012.11.020.

10. Boudjema Z., Taleb R., Yahdou A., Bouyekni A. Fuzzy second order sliding mode control of a doubly-fed induction machine supplied by two matrix converters. Journal of Electrical Engineering, 2015, vol.15, no.3, pp. 308-317.

11. Rahimi M. Drive train dynamics assessment and speed controller design in variable speed wind turbines. Renewable Energy, 2016, vol.89, pp. 716-729. doi: 10.1016/j.renene.2015.12.040.

12. Talha A., Berkouk El Madjid, Francois B., Boucherit M.S. Modeling and Control of a Power Electronic Cascade for the Multi DC Bus Supply of a Seven-Level NPC Voltage Source Inverter. 2006 12th International Power Electronics and Motion Control Conference, Aug. 2006. doi: 10.1109/epepemc.2006.4778399.

13. Rodriguez J., Bernet S., Steimer P.K., Lizama I.E. A Survey on Neutral-Point-Clamped Inverters. IEEE Transactions on Industrial Electronics, 2010, vol.57, no.7, pp. 2219-2230. doi: 10.1109/tie.2009.2032430.

14. Huang Jing, Corzine K.A. Extended operation of flying capacitor multilevel inverters. IEEE Transactions on Power Electronics, 2006, vol.21, no.1, pp. 140-147. doi: 10.1109/tpel.2005.861108.

15. Babaei E. A Cascade Multilevel Converter Topology With Reduced Number of Switches. IEEE Transactions on Power Electronics, 2008, vol.23, no.6, pp. 2657-2664. doi: 10.1109/tpel.2008.2005192.

16. Kouro S., Malinowski M., Gopakumar K., Pou J., Franquelo L.G., Bin Wu, Rodriguez J., Pérez M.A., Leon J.I. Recent Advances and Industrial Applications of Multilevel Converters. IEEE Transactions on Industrial Electronics, 2010, vol.57, no.8, pp. 2553-2580. doi: 10.1109/tie.2010.2049719. 
17. Tolbert L.M., Fang Zheng Peng, Habetler T.G. Multilevel converters for large electric drives. IEEE Transactions on Industry Applications, 1999, vol.35, no.1, pp. 36-44. doi: $\mathbf{1 0 . 1 1 0 9 / 2 8 . 7 4 0 8 4 3 . ~}$

18. Rodriguez J., Franquelo L.G., Kouro S., Leon J.I., Portillo R.C., Prats M.A.M., Perez M.A. Multilevel Converters: An Enabling Technology for High-Power Applications. Proceedings of the IEEE, 2009 vol.97, no.11, pp. 1786-1817. doi: 10.1109/jproc.2009.2030235.

19. Song-Manguelle J., Mariethoz S., Veenstra M., Rufer A.A Generalized Design Principle of a Uniform Step Asymmetrical Multilevel Converter for High Power Conversion. European Conference on Power Electronics and Applications, EPE'01, Graz, Austria, August 2001.

20. López J., Sanchis P., Roboam X., Marroyo L. Dynamic Behavior of the Doubly Fed Induction Generator During ThreePhase Voltage Dips. IEEE Transactions on Energy Conversion, 2007, vol.22, no.3, pp. 709-717. doi: 10.1109/tec.2006.878241.

21. Boudjema Z., Taleb R., Yahdou A. A New DTC Scheme using Second Order Sliding Mode and Fuzzy Logic of a DFIG for Wind Turbine System. International Journal of Advanced Computer Science and Applications, 2016, vol.7, no.8. doi: 10.14569/ijacsa.2016.070808.

22. Li L.-B., Sun L.-L., Zhang S.-Z., Yang Q.-Q. Speed tracking and synchronization of multiple motors using ring coupling control and adaptive sliding mode control. ISA Transactions, 2015, vol.58, pp. 635-649. doi: 10.1016/j.isatra.2015.07.010.

23. Chen H., Ding K., Zhou X., Fu K., Qu Y. A novel adaptive sliding mode control of PWM rectifier under unbalanced grid voltage conditions based on direct power control. Proceedings of the 33rd Chinese Control Conference, Jul. 2014. doi: 10.1109/chicc.2014.6896603.

24. Sahoo S.R., Brisilla R.M., Sankaranarayanan V. Disturbance observer based adaptive sliding mode control: An application to single machine infinite bus power system. 2015 IEEE International Conference on Signal Processing, Informatics, Communication and Energy Systems (SPICES), Feb. 2015. doi: 10.1109/spices.2015.7091544.

25. Lee D., Vukovich G. Adaptive sliding mode control for spacecraft body-fixed hovering in the proximity of an asteroid. Aerospace Science and Technology, 2015, vol.46, pp. 471-483. doi: 10.1016/j.ast.2015.09.001.

26. Shahriari kahkeshi M., Sheikholeslam F., Zekri M. Design of adaptive fuzzy wavelet neural sliding mode controller for uncertain nonlinear systems. ISA Transactions, 2013, vol.52, no.3, pp. 342-350. doi: 10.1016/j.isatra.2013.01.004.
27. Do H.T., Park H.G., Ahn K.K. Application of an adaptive fuzzy sliding mode controller in velocity control of a secondary controlled hydrostatic transmission system. Mechatronics, 2014, vol.24, no.8, pp. 1157-1165. doi: 10.1016/j.mechatronics.2014.09.003.

28. Khazaee M., Markazi A.H.D., Omidi E. Adaptive fuzzy predictive sliding control of uncertain nonlinear systems with bound-known input delay. ISA Transactions, 2015, vol.59, pp. 314-324. doi: 10.1016/j.isatra.2015.10.010.

29. Mirzaei M., Nia F.S., Mohammadi H. Applying adaptive fuzzy sliding mode control to an underactuated system. The 2nd International Conference on Control, Instrumentation and Automation, Dec. 2011. doi: 10.1109/icciautom.2011.6356736. 30. Zou Y., Elbuluk M.E., Sozer Y. Stability Analysis of Maximum Power Point Tracking (MPPT) Method in Wind Power Systems. IEEE Transactions on Industry Applications, 2013, vol.49, no.3, pp. 1129-1136. doi: 10.1109/tia.2013.2251854.

31. Taleb R., Derrouazin A. USAMI Control with a Higher Order Harmonics Elimination Strategy based on the Resultant Theory. International Conference on Technologies and Materials for Renewable Energy, Environment and Sustainability, TMREES'14, Beirut, Lebanon, 10-13 April 2014. 32. Bouchafaa F. Etude et commande de différentes cascades à onduler à neuf niveaux à structure NPC. Application à la conduite d'une MSAP, Ph.D. thesis, ENP, Algiers, Algeria, 2008. (Fra).

33. Abdin E.S., $\mathrm{Xu}$ W. Control design and dynamic performance analysis of a wind turbine-induction generator unit. IEEE Transactions on Energy Conversion, 2000, vol.15, no.1, pp. 91-96. doi: 10.1109/60.849122.

34. Huang Y.-J., Kuo T.-C., Chang S.-H. Adaptive SlidingMode Control for Nonlinear Systems With Uncertain Parameters. IEEE Transactions on Systems, Man, and Cybernetics, Part B (Cybernetics), 2008, vol.38, no.2, pp. 534539. doi: 10.1109/tsmcb.2007.910740.

Received 02.02.2018

Mohamed Benkahla ${ }^{1}$

Rachid Taleb ${ }^{1}$, Associate Professor,

Zinelaabidine Boudjema ${ }^{1}$, Associate Professor,

${ }^{1}$ Electrical Engineering Department,

Hassiba Benbouali University, LGEER Laboratory,

Chlef, Algeria.

e-mail: med89.benkahla@gmail.com

\section{How to cite this article:}

Benkahla M., Taleb R., Boudjema Z. A new robust control using adaptive fuzzy sliding mode control for a DFIG supplied by a 19-level inverter with less number of switches. Electrical engineering \& electromechanics, 2018, no.4, pp. 11-19. doi: 10.20998/2074-272X.2018.4.02. 